\title{
Fibrinolytic potential is significantly increased by oestrogen treatment in postmenopausal women with mild dyslipidaemia
}

O C E Gebara, M A Mittleman, B W Walsh, I Lipinska, F K Welty, G Bellotti, J E Muller, F K Sacks, G H Tofler

\begin{abstract}
Objective-To study the effects of oestrogen replacement treatment on fibrinolytic potential in postmenopausal women.

Design-Randomised, double blind, placebo controlled trial of oral 17及oestradiol.

Setting-Subjects were evaluated in the outpatient setting.

Patients-Nineteen postmenopausal women with mild dyslipidaemia, aged 44 to 69 years (mean (SD) 55.7 (6.7)).

Main outcome measures-Fibrinolytic activity (fibrin plate assay) and tissue plasminogen activator (t-PA) antigen were measured at baseline and after three, six, and nine weeks of each treatment.

Results-After nine weeks of 2 mg oestradiol treatment, there was a significant increase in fibrinolytic potential compared with placebo, as indicated by an increase in fibrinolytic activity (mean (SEM), 80 (9) $v 54$ (5) $\mathrm{mm}^{2}$ of lysis in the fibrin plate, $2 \mathrm{mg} v$ placebo, $p=0.002$ ) and a decrease in t-PA antigen (5.8 (0.9) $v$ $8.4(1.2) \mathrm{ng} / \mathrm{ml}, 2 \mathrm{mg} v$ placebo, $\mathrm{p}<0.001)$. There was a similar trend with the $1 \mathrm{mg}$ dose but the changes were less noticeable. Conclusions-Hormone replacement treatment with $17 \beta$-oestradiol for nine weeks significantly increased fibrinolytic potential in postmenopausal women with mild dyslipidaemia. This suggests that the cardioprotective effect of oestrogen may be mediated, in part, by an increase in fibrinolytic potential.
\end{abstract}

(Heart 1998;80:235-239)

Keywords: oestrogen; fibrinolysis; randomised controlled trial; dyslipidaemia

Observational studies suggest a major cardioprotective effect of oestrogen in postmenopausal women ${ }^{1-3}$ but the mechanism has not been completely explained. Reported effects of exogenous oestrogen include an increase in high density lipoprotein cholesterol and a decrease in total and low density lipoprotein cholesterol, ${ }^{45}$ an improvement in carbohydrate metabolism, ${ }^{6}$ direct vascular effects that are both endothelium dependent ${ }^{7}$ and endothelium independent, ${ }^{8}$ and more recently, an antioxidant effect. ${ }^{9}$

Recent findings also suggest that oestrogen may have a beneficial effect on risk by reducing thrombotic tendency. This is in contrast to reports that synthetic oestrogens used in oral contraceptives promote thrombosis. ${ }^{10}$ Postmenopausal natural oestrogen replacement has been associated with a favourable decrease in prothrombotic factors such as fibrinogen, ${ }^{5} 1112$ although in a placebo controlled trial conjugated oestrogens have also been shown to increase plasma levels of fibrinopeptide $A$ and $F_{1+2}$ fragments, suggesting enhanced thrombin generation. ${ }^{13}$ If that occurs, an increase in the fibrinolytic potential could provide a counterbalancing effect. In findings from the Framingham offspring study, ${ }^{14}$ which are supported by other observational data, ${ }^{15}$ our group has shown an association between a higher oestrogen status (premenopausal women and postmenopausal women receiving oestrogen replacement treatment), and increased fibrinolytic potential. ${ }^{14}$ Several prospective studies support a role for the fibrinolytic system in the development of vascular diseases, by showing that impaired fibrinolysis-as assessed by low fibrinolytic activity ${ }^{17}{ }^{18}$ and high concentrations of plasminogen activator inhibitor (PAI-1) ${ }^{19-20}$ and tissue plasminogen activator antigen $(\mathrm{t}-\mathrm{PA})^{21}$-predicted an increased risk of myocardial infarction and stroke.

Because of the potential limitations of observational studies, we employed a randomised, double blind, placebo controlled crossover design to investigate the effect of two doses of postmenopausal oestrogen replacement treatment on fibrinolytic potential.

\section{Methods}

STUDY POPULATION

Nineteen postmenopausal women participated in the study. They were aged 44 to 69 years, mean (SEM), 55.7 (6.7) years. Women were eligible if they had not received hormone replacement treatment for at least two months before the study, and their menopause had

Table 1 Clinical characteristics of the population

\begin{tabular}{lll}
\hline & Mean (SD) & Range \\
\hline Age (years) & $55.6(6.7)$ & 44 to 69 \\
Weight (kg) & $68.0(11)$ & 52.1 to 85 \\
Height (m) & $1.62(0.08)$ & 1.44 to 1.81 \\
Time since menopause (years) & $8.0(6.7)$ & 1 to 23 \\
Previous use of HRT (n) & $17(89.5 \%)$ & - \\
Cause of menopause & & \\
$\quad$ Natural (n) & $17(89.5 \%)$ & - \\
Cholesterol (mg/dl) & & \\
$\quad$ Total & $222(17)$ & 195 to 259 \\
$\quad$ HDL & $61(12)$ & 44 to 92 \\
$\quad$ LDL & $146(16)$ & 126 to 169 \\
Triglycerides (mg/dl) & $111(50)$ & 73 to 280 \\
\hline
\end{tabular}

HDL, high density lipoprotein; HRT, hormone replacement therapy; LDL, low density lipoprotein.
Accepted for publication 24 April 1998 


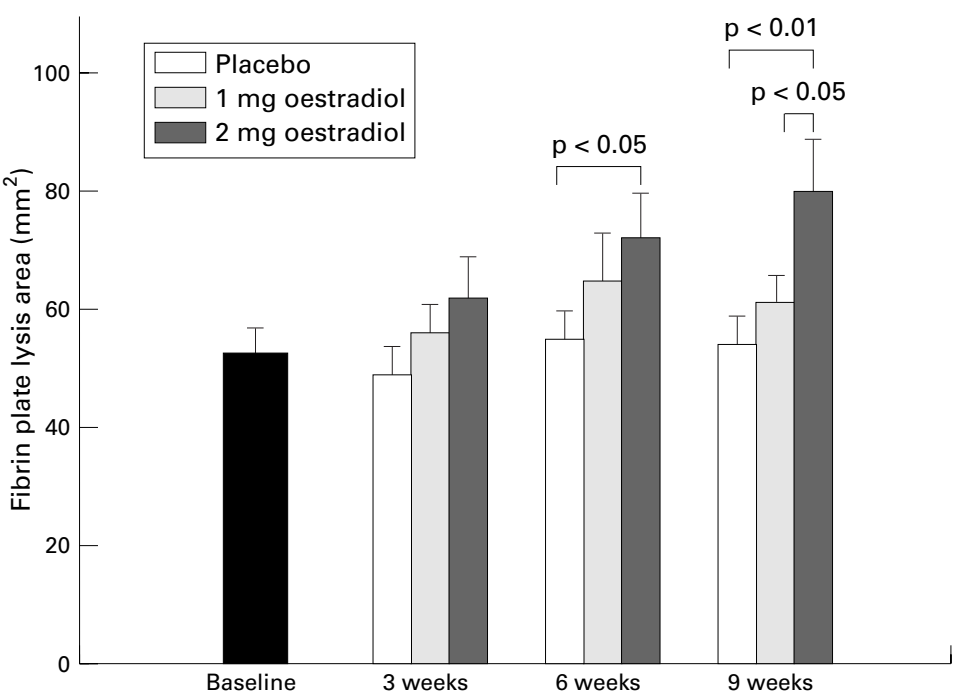

Figure 1 Fibrinolytic activity during the three treatment phases. The $2 \mathrm{mg}$ dose of $17 \beta$-oestradiol produced a significant increase in fibrinolytic activity compared with placebo after six and nine weeks of treatment. The increase with the $1 \mathrm{mg}$ dose was not as great.

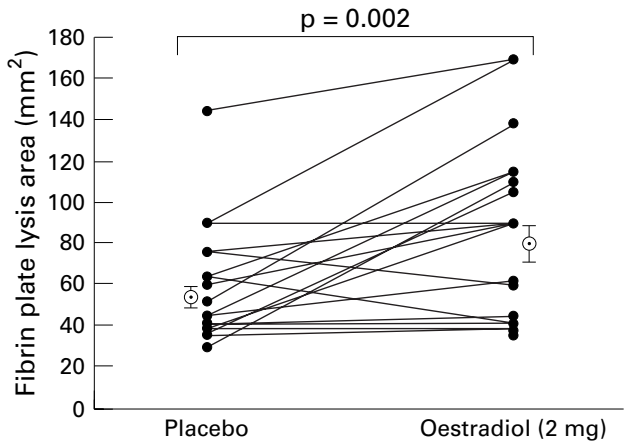

Figure 2 Changes in fibrinolytic activity levels between placebo and $2 \mathrm{mg}$ dose of $17 \beta$-oestradiol after nine weeks of treatment. Mean values with SEM are also shown.

occurred at least one year previously. Menopause was confirmed by serum follicle stimulating hormone levels. Because the effect of oestrogen replacement on lipoprotein metabolism was also evaluated in this study, women were required to have mild hypercholesterolaemia (serum cholesterol between 200 and $240 \mathrm{mg} / \mathrm{dl}(5.17$ to $6.20 \mathrm{mmol} / \mathrm{l})$ and an LDL cholesterol between 130 and $160 \mathrm{mg} / \mathrm{dl}(3.36$ to $4.13 \mathrm{mmol} / \mathrm{l}$ ). The results of the lipid analysis will be reported separately. Exclusion criteria were hypertension, diabetes mellitus, tobacco use, obesity (body weight $>135 \%$ of ideal weight), history of breast or uterine cancer, thromboembolism, or liver, renal or cardiovascular disease. Initial evaluation included a history, physical examination, Papanicolau smear, complete blood count, and

Table 2 Effect of $17 \beta$-oestradiol on fibrinolytic activity and tissue plasminogen activator antigen $(t-P A)$ after nine weeks of treatment

\begin{tabular}{|c|c|c|c|}
\hline & \multirow{3}{*}{$\begin{array}{l}\text { Placebo (mean } \\
(S E M))\end{array}$} & \multicolumn{2}{|l|}{$17 \beta$-oestradiol } \\
\hline & & $1 \mathrm{mg}$ & $2 m g$ \\
\hline & & \multicolumn{2}{|c|}{ 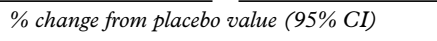 } \\
\hline Fibrinolytic activity $\left(\mathrm{mm}^{2}\right)$ & $54(5)$ & $\begin{array}{l}+13(-13 \text { to }+42) \\
(\mathrm{p}=0.332)\end{array}$ & $\begin{array}{l}+48(+13 \text { to }+87)^{\star} \\
(\mathrm{p}=0.002)\end{array}$ \\
\hline $\mathrm{t}-\mathrm{PA}(\mathrm{ng} / \mathrm{ml})$ & $8.3(1.2)$ & $\begin{array}{l}-18(-1 \text { to }-31) \\
(\mathrm{p}=0.043)\end{array}$ & $\begin{array}{l}-31(-17 \text { to }-41) \\
(\mathrm{p}<0.001)\end{array}$ \\
\hline
\end{tabular}

${ }^{\star} \mathrm{p}<0.05 v$ percentage change for $1 \mathrm{mg} 17 \beta$-oestradiol. routine clinical chemistry. The study was approved by the hospital institutional review board, and all participants gave written informed consent.

Eligible patients were placed on a low cholesterol American Heart Association step I diet for six weeks before randomisation. Patients were initially randomly assigned to one of three treatment groups: $1 \mathrm{mg}$ or $2 \mathrm{mg}$ oral $17 \beta$-oestradiol (Estrace, Mead Johnson, Evansville, Indiana, USA) daily, or placebo. At the conclusion of each nine week treatment period, the patients were given $10 \mathrm{mg}$ of progestin (Provera, Upjohn, Kalamazoo, Michigan, USA) daily for 10 days to shed any stimulated endometrium. After three weeks off treatment, subjects crossed over to the next treatment regimen. All patients received placebo and the two doses of oestradiol in random order.

BLOOD SAMPLING AND ANALYSIS

Blood samples were collected at baseline, and after three, six, and nine weeks of each treatment regimen. For determination of fibrinolytic activity and t-PA antigen levels, blood was collected between 08:00 and 10:00 from an antecubital vein after an overnight fast into tubes containing EDTA. Plasma was separated by centrifugation at $2500 \times g$ for 30 minutes at $4^{\circ} \mathrm{C}$. Plasma aliquots were frozen and stored at $-70^{\circ} \mathrm{C}$ for subsequent analysis. Fibrinolytic activity in euglobulin fraction was determined on fibrin plates in duplicates as previously described. ${ }^{22}$ The area of lysis achieved in the fibrin plate (in $\mathrm{mm}^{2}$ ) 18 to 20 hours after the addition of a $30 \mu \mathrm{l}$ of the euglobulin precipitate was measured, and the average of the two determinations taken. Levels of t-PA antigen were measured in duplicate using a commercially available kit from Biopool (TintElize t-PA, Umea, Sweden), following a procedure described by Ranby et $a .^{23}$ The intra-assay coefficient of variation in our laboratory was $8.0 \%$ for the fibrin plate assay and $5.5 \%$ for t-PA antigen.

\section{STATISTICAL ANALYSIS}

Logarithmic transformation was performed on the variables to achieve normality, and geometric means are presented. Treatment and treatment order effect was evaluated using analysis of variance (ANOVA) for repeated measures, with the Student-Newman-Keuls method for multiple comparisons. Two tailed $\mathrm{p}$ values $<0.05$ were considered significant. All values are presented as mean (SEM). Confidence intervals were calculated using standard analytical methods.

\section{Results}

Table 1 shows the demographic and clinical characteristics of the population studied. All women were healthy postmenopausal subjects with mild hypercholesterolaemia.

\section{EFFECT ON FIBRINOLYTIC ACTIVITY}

The data are shown in figs 1 and 2 and in table 2. Fibrinolytic activity increased significantly after the administration of $2 \mathrm{mg}$ oestradiol for 


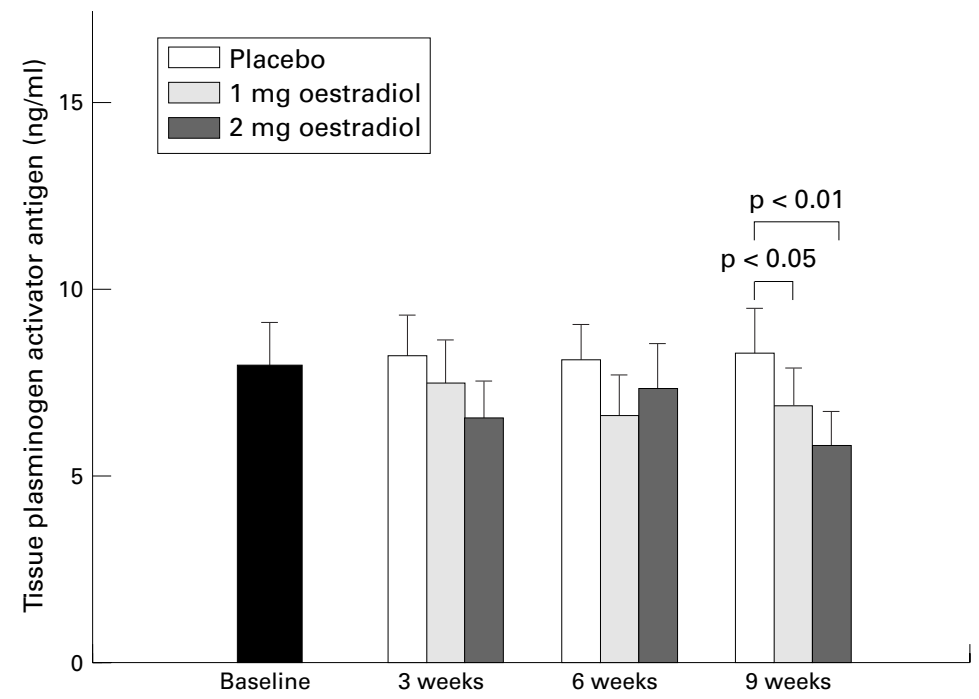

Figure 3 Tissue plasminogen activator antigen ( $t-P A)$ levels during the three treatment phases. The $2 \mathrm{mg}$ dose of $17 \beta$-oestradiol produced a significant decrease in $t$-PA antigen concentrations compared with placebo effect after nine weeks of treatment, corresponding to an increase in the fibrinolytic potential (see text).

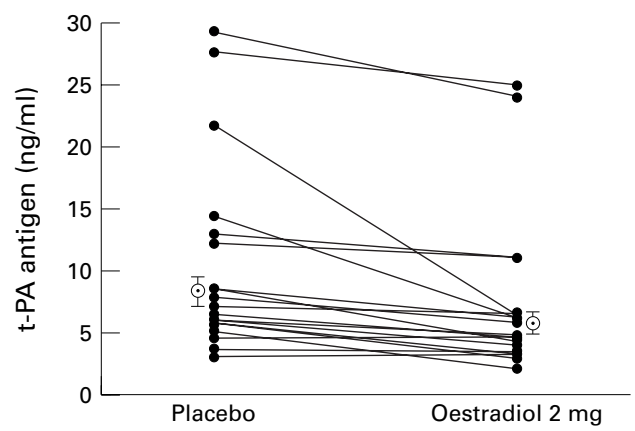

Figure 4 Changes in plasma levels of tissue plasminogen activator antigen $(t-P A)$ between placebo and $2 \mathrm{mg}$ dose of $17 \beta$-oestradiol after nine weeks of treatment. Mean values with SEM are also shown.

nine weeks when compared with placebo $(80$ (9) $v 54$ (5) $\mathrm{mm}^{2}, 2 \mathrm{mg} v$ placebo, $\mathrm{p}=0.002$ ). This was a $48 \%$ increase in fibrinolytic activity (95\% confidence interval $13 \%$ to $87 \%$, $\mathrm{p}=0.002)$. The increase in fibrinolytic activity was already present after six weeks of treatment. The $1 \mathrm{mg}$ dose of oestradiol tended to increase the fibrinolytic activity but the change did not reach significance.

EFFECT ON t-PA ANTIGEN

These data are shown in figs 3 and 4 and in table 2. Mean (SEM) t-PA antigen concentration after treatment with $2 \mathrm{mg}$ oestradiol for nine weeks was $5.8(0.9) \mathrm{ng} / \mathrm{ml}$, significantly lower than after placebo treatment $(8.3$ (1.2) $\mathrm{ng} / \mathrm{ml}, \mathrm{p}<0.001)$. This was a $31 \%$ decrease $(95 \%$ confidence interval $17 \%$ to $41 \%, \mathrm{p}<0.001)$. The $1 \mathrm{mg}$ oestradiol treatment also decreased t-PA antigen concentrations after nine weeks: $6.9(1.0) v 8.3(1.2) \mathrm{ng} /$ $\mathrm{ml}, 1 \mathrm{mg} v$ placebo, $\mathrm{p}=0.043$.

To assess the possibility of a carryover effect from each treatment phase into the next one, we compared the baseline values of the variables in each phase. No significant differences were found.

\section{Discussion}

Our results indicate that hormone replacement treatment with $17 \beta$-oestradiol increased the fibrinolytic potential within nine weeks of treatment. These results extend previous observations of an association between high oestrogen status (postmenopausal women receiving oestrogen replacement and premenopausal state) and heightened fibrinolytic potential. ${ }^{14}$ The increase in fibrinolytic potential represents a potential mechanism for the cardioprotective effect of oestrogen replacement treatment among postmenopausal women.

IMPAIRED FIBRINOLYSIS AND CORONARY HEART DISEASE

Most cross sectional studies of patients with coronary artery disease have shown decreased fibrinolytic activity compared with control subjects. ${ }^{17}$ While impaired fibrinolysis has chiefly been evaluated using plasminogen activator inhibitor (PAI-1), ${ }^{20}$ high concentrations of t-PA antigen also reflect impairment of the fibrinolytic system, as most of the t-PA antigen measured is complexed with PAI-1 and is inactive. ${ }^{24}$ Concentrations of t-PA antigen and PAI-1 antigen are shown to be highly correlated. ${ }^{25}$ Prospective studies have also shown that raised t-PA antigen concentrations predict an increased risk of infarction in asymptomatic men, ${ }^{21}$ and an increased mortality in subjects with coronary artery disease. ${ }^{26}$ A recent prospective study showed that among the fibrinolytic variables evaluated, high t-PA antigen concentrations were associated with the highest relative risk of subsequent coronary events in the follow up. ${ }^{27}$ In the present study, we determined fibrinolytic potential using two different assays: activity in euglobulin fractions (a global measure of fibrinolytic activity) and t-PA antigen.

OESTROGEN AND FIBRINOLYSIS

Our findings that $17 \beta$-oestradiol produced an increase in fibrinolytic potential confirm previous observational studies of postmenopausal women receiving oestrogen alone ${ }^{1415}$ or a combination of oestrogen and progestin. ${ }^{12}$ Sporrong and colleagues found similar results when measuring plasminogen activator inhibitor activity. ${ }^{28}$ Recently, Koh and coworkers showed that after only four weeks of treatment with conjugated equine oestrogen there was an increase in fibrinolytic potential as measured by decreased levels of PAI- 1 antigen. ${ }^{29}$ The increased fibrinolysis in the present study became significant after six weeks and disappeared during placebo treatment, suggesting that this potential component of the cardioprotective effect can be gained quickly but is mainly limited to the time during which the subjects are taking oestrogen. These data are consistent with findings from observational studies that the cardiovascular benefit of hormone replacement treatment is predominantly present during active treatment and is reduced when treatment is discontinued. ${ }^{12}$ In the present study, we also demonstrated a dose related effect. 
As activation of the coagulation system has also been reported with oral contraceptives and postmenopausal oestrogen treatment, ${ }^{10}{ }^{13}$ the increase in fibrinolytic potential may counterbalance a harmful effect on coagulation. Although an overall increase in fibrinolytic potential after oestrogen treatment was observed in our study, some women did not show changes in the fibrinolytic variables. In these subjects, the potential activation of the coagulation system ${ }^{13}$ may be harmful.

The mechanism by which oestrogen may increase the fibrinolytic potential is not clear. As oestrogen receptors have been demonstrated on endothelial cells, ${ }^{3031}$ it is possible that oestrogen may directly influence the biosynthesis and secretion of t-PA and PAI-1 from the endothelium. ${ }^{32}$ Supporting this are the observations that PAI-1 production is influenced by other hormones, ${ }^{33}$ and that oestrogen modifies the production and secretion of other endothelium derived substances such as nitric oxide. ${ }^{34}$ However, in two studies, incubation of endothelial cells with oestrogen did not change PAI-1 production. ${ }^{10}{ }^{35}$ The fibrinolytic effect of oestrogen could act through an antioxidant effect. By inhibiting oxidisation of low density lipoproteins, ${ }^{9}$ oestrogen treatment could make these particles less effective in stimulating PAI-1 production by endothelial cells. ${ }^{36}$ In addition, oestrogen acts on carbohydrate metabolism, reducing plasma insulin and decreasing insulin resistance. ${ }^{6}$ As insulin stimulates the synthesis of PAI-1 in vitro ${ }^{37}$ and in vivo, ${ }^{38}$ a reduction of insulin levels by oestrogen might result in lower PAI-1 secretion and less inhibition of the fibrinolytic system. It is also possible that there is increased clearance of t-PA/PAI-1 complexes owing to oestrogen mediated upregulation of liver function. These mechanisms should be investigated in further trials.

\section{LIMITATIONS}

As the study participants had mild hypercholesterolaemia, the results cannot necessarily be extrapolated to postmenopausal women whose cholesterol levels are normal. However, a consistent association between oestrogen status and fibrinolysis has been demonstrated in observational studies after adjustment for lipid levels, ${ }^{14}{ }^{15}$ and in a clinical trial of healthy women. ${ }^{29}$ The importance of fibrinolytic indices as risk factors in women requires further investigation because previous studies have primarily been conducted in men, although a recent report showed that the activity of euglobulin fractions is an important marker of risk for women. ${ }^{18}$ As the blood samples for the present study were collected in EDTA, we were unable to make reliable measurements of PAI-1 antigen, an important marker of impairment of the fibrinolytic system. However, t-PA antigen also provides a measure of the fibrinolytic potential, which is strongly correlated with PAI-1 antigen, and has been shown to be an important predictor of events. ${ }^{27}$ Furthermore our study complements that of Koh et al, who measured PAI- $1 .^{29}$ Finally, the effect of combined oestrogen-progestin preparations on fibrinolytic potential requires further study, although there are suggestions from observational data, ${ }^{14}$ but not from a controlled trial, ${ }^{29}$ that there may be partial attenuation of the effect of oestrogen alone. The effects of transdermal oestradiol should also be assessed in future investigations.

In conclusion, our finding that treatment of postmenopausal women with oral $17 \beta-$ oestradiol increases fibrinolytic potential suggests that the reduction of cardiovascular risk associated with oestrogen treatment may in part be the result of a reduction in thrombotic tendency.

Support for the study was provided by Mead-Johnson Pharmaceuticals.

1 Stampfer MJ, Colditz GA. Estrogen replacement therapy and coronary heart disease: a quantitative assessment of the epidemiologic evidence. Prev Med 1991;20:47-63.

Wenger NK, Speroff L, Packard B. Cardiovascular health and disease in women. $N$ Engl F Med 1993;329:247-56.

3 Grodstein F, Stampfer MJ, Colditz GA, et al. Postmenopausal hormone therapy and mortality. $N$ Engl $f$ Med sal hormone thera

4 Walsh BW, Schiff I, Rosner B, et al. Effects of postmenopaual estrogen replacement on the concentrations and metabolism of plasma lipoproteins. $N$ Engl $f$ Med 991;325:1196-204.

5 The Writing Group for the PEPI Trial. Effects of estrogen or estrogen/progestin regimens on heart disease risk factors in postmenopausal women. The postmenopausal estrogen/ progestin interventions (PEPI) trial. $\mathscr{F} A M A$ 1995;273:199208.

6 Barrett-Connor E, Laakso M. Ischemic heart disease in postmenopausal women: effects of estrogen use on glucose and insulin levels. Arteriosclerosis 1990;10:531-4.

7 Lieberman EH, Gerhard MD, Uehata A, et al. Estrogen improves endothelium-dependent, flow-mediated, vasodilation in postmenopausal women. Ann Intern Med 1994; 121:936-41.

8 Mugge A, Riedel $M$, Barton $M$, et al. Endothelium Mugge A, Riedel $M$, Barton $M$, et al. Endothelium
independent relaxation of human coronary arteries by $17 \beta-$ independent relaxation of human coronary arteries by
oestradiol in vitro. Cardiovasc Res 1993;27:1939-42.

9 Sack MN, Rader DJ, O'Cannon RO. Oestradiol and inhibition of oxidation of low-density lipoproteins in postmenopausal women. Lancet 1994;343:269-70.

10 Kooistra T, Bosma PJ, Jespersen J, et al. Studies on the mechanism of action of oral contraceptives with regard to fibrinolytic variables. Am $\mathcal{F}$ Obstet Gynecol 1990;163:40412.

11 Nabulsi AA, Folsom AR, White A, et al. Association of hormone-replacement therapy with various cardiovascular risk factors in postmenopausal women. $N$ Engl $7 \mathrm{Med}$ 1993;328:1069-75.

12 Scarabin PY, Plu-Bureau G, Bara L, et al. Haemostatic variables in menopausal status: influence of hormone replacement therapy. Thromb Haemost 1993;70:584-7.

13 Caine YG, Bauer KA, Barzegar S, et al. Coagulation factors following estrogen administration to postmenopausal following estrogen administration to
women. Thromb Haemost 1992;68:392-5.

14 Gebara OCE, Mittleman MA, Sutherland P, et al. Association between increased estrogen status and increased fibrinolytic potential in the Framingham offspring study. Circulation 1995;91:1952-8.

15 Shahar E, Folsom AR, Salomaa VV, et al. Relation of hormone-replacement therapy to measures of plasma fibrinolytic activity. Circulation 1996;93:1970-5.

16 Meilahn EN, Kuller LH, Matthews KA, et al. Hemostatic factors according to menopausal status and use of hormone replacement therapy. Ann Epidemiol 1992;2:445-55.

17 Prins MH, Hirsh J. A critical review of the relationship between impaired fibrinolysis and myocardial infarction. Am Heart f 1991;122:545-51.

18 Meade TW, Cooper JA, Chakrabarti R, et al. Fibrinolytic activity and clotting factors in ischaemic heart disease in activity and clotting factors in
women. $B M \mathcal{F} 1996 ; 312: 1581$.

19 Kruithof EKO. Plasminogen activator inhibitor type 1: biochemical, biological and clinical aspects. Fibrinolysis 1988; 2:59-70.

20 Hamsten A, Walldius G, Szamosi A, et al. Plasminogen activator inhibitor in plasma: a risk factor for recurrent myocardial infarction. Lancet 1987;ii:3-9.

21 Ridker PM, Vaughan DE, Stampfer MJ, et al. Endogenous tissue-type plasminogen activator and risk of myocardial infarction. Lancet 1993;341:1165-8.

22 Brakman P. Fibrinolysis: a standardized fibrin plate method and fibrinolytic assay of plasminogen. Amsterdam: Scheltema and Halkema, 1967:1-124.

23 Ranby M, Bergsdorf N, Nilsson T, et al. Age dependence of tissue plasminogen activator concentrations in plasma, as studied by an improved enzyme linked immunosorbent assay. Clin Chem 1986;32:2160-5. 
24 Urden G, Hamsten A, Wiman B. Comparison of plasminogen activator inhibitor activity and antigen in plasma samgen activator inhibitor activity and anti
ples. Clin Chim Acta 1987;169:189-96.

25 Marckmann P, Sandstrom B, Jepersen J. The variability of and associations between measures of blood coagulation fibrinolysis and blood lipids. Atherosclerosis 1992;96:235-44

26 Thompson SG, Kienast J, Pyke SDM, et al, for the ECAT Angina Pectoris Study. Hemostatic factors and the risk of myocardial infarction or sudden death in patients with angina pectoris. N Engl F Med 1995;332:635-41.

27 Juhan-Vague I, Pyke SDM, Alessi MC, et al. Fibrinolytic factors and the risk of myocardial infarction or sudden death in patients with angina pectoris. Circulation 1996;94: 2057-63.

28 Sporrong T, Mattsson L, Samsioe G, et al. Haemostatic changes during continuous oestradiol-progestogen treatment of postmenopausal women. Br f Obst Gynaecol 1990;

29 Koh KK, Mincemoyer R, Bui MN, et al. Effects of hormone-replacement therapy on fibrinolysis in postmenohormone-replacement therapy on fibrinolysis in

30 Karas RH, Patterson BL, Mendelsohn ME. Human vascular smooth muscle cells contain functional estrogen recep-

31 Losordo DW, Kearney M, Kim EA, et al. Variable expression of the estrogen receptor in normal andatherosclerotic coronary arteries of premenopausal women. Circulation 1994;89:1501-10.
32 Raghunath PN, Tomaszewski JE, Brady ST, et al. Plasminogen activator system in human coronary atherosclerosis. Arterioscler Thromb Vasc Biol 1995;15:1432-43.

33 Andreasen PA, Georg B, Lund LR, et al. Plasminogen activator inhibitors: hormonally regulated serpins. Mol Cell Endocrinol 1990;68:1-19.

34 Collins P, Shay J, Jiang C, et al. Nitric oxide accounts for dose-dependent endothelium-dependent, flow-mediated coronary relaxation after acute estrogen withdrawal. Circulation 1994;90:1964-8.

35 Quehenberger P, Kapiotis S, Partan C, et al. Studies on oral contraceptive-induced changes in blood coagulation and fibrinolysis and the estrogen effect on endothelial cells. Ann Hematol 1993;67:33-6.

36 Kugiyama K, Sakamoto T, Misumi T, et al. Transferable lipids in oxidized low-density lipoprotein stimulate plasminogen activator inhibitor-1 and inhibit tissue-type plasminogen activator release from endothelial cells. Circ Res 1993; 73:335-43.

37 Kooistra T, Bosma PJ, Tons HAM, et al. Plasminogen activator inhibitor 1: biosynthesis and mRNA level are increased by insulin in cultured human hepatocytes. Thromb Haemost 1989;62:723-8.

38 Nordt TK, Sawa H, Fujii S, et al. Induction of plasminogen activator inhibitor type-1 (PAI-1) by proinsulin and insulin in vivo. Circulation 1995;91:764-70. 